\title{
Studies on Construction Technical System of Ecological Irrigation District in the Lower Yellow River Basin
}

\author{
Shuang Zhang ${ }^{1,2}$ and Guibin Pang ${ }^{3 *}$ \\ ${ }^{1}$ Han-dun Irrigation Management Bureau of Binzhou city, Binzhou, China; \\ ${ }^{2}$ School of civil engineering, Shandong University, Jinan, China; \\ ${ }^{3}$ School of Resources and Environment, University of Jinan, Jinan, China; \\ Corresponding Email: stu_panggb@ujn.edu.cn
}

\begin{abstract}
Under the background of global water crisis, the construction of ecological irrigation district has become the inevitable trend of the development of irrigation district and new rural construction. In this paper, Handun Irrigation District in the lower Yellow River Basin, as the research object, through analyzing the present operation situation and the existing problems, the technical system of ecological irrigation district in the lower Yellow River Basin are constructed, including water and sediment regulation, saline-alkali land management, efficient use of water resources, water environment protection, irrigation management, water culture and landscape. Finally, a series of the feasibility measures are proposed, including engineering measures, management measures and ecological measures, which has an important reference value for construction of ecological irrigation district in the lower Yellow River Basin.
\end{abstract}

Keywords. Yellow River irrigation district, ecological irrigation district, constriction, measures

\section{Introduction}

The Irrigation District in the lower Yellow River Basin is one of the largest continuous gravity irrigation area, there are 104 Yellow River irrigation districts, involving more than 70 cities, covering irrigation area of 1.9 million $\mathrm{hm}^{2}$, which play a very important role of agricultural development, urban and rural water supply and ecological environment in the lower Yellow River Basin. In recent years, the construction of irrigation district has always been to engineering benefit maximization as the goal, the regional ecological and environmental quality are ignored, combined with the global climate extremes, irrigation district water environment deterioration, soil quality degradation, farmland non-point source pollution, decline of biodiversity, ecosystem destruction and so on, a series of outstanding problems which restrict the development of the irrigation district sustainable future constantly emerging, this requires irrigation district must be from a single production functions to convert to ensure the safety of food security, water supplyment, water-saving society construction and water ecological environment protection, rural landscape construction and so on. Water ecological civilization should be as a guide to the construction of the new stage in the irrigation district, highlighting the efficient utilization of water resources and ecological environment protection as well as the surrounding supporting system are the main content of ecological irrigation district construction $[1,2]$. The construction of ecological irrigation district become a necessary guarantee of our country food security and water security.

\section{Material and methods}

Handun Irrigation District was founded in 1958, located in the hinterland of the Yellow River delta. Scope of irrigation area in Zhanhua, Bincheng and Lijin county, 13 townships, 504 natural villages. The east of irrigation district is Chuguan river and Maxin river, the west of irrigation district is Qintai ditch and Qinkou river, the south is Yellow River, and the bohai sea in the north. There are 0.15 million $\mathrm{hm}^{2}$ total area, 0.08 million hm² arable land, 0.064 million $\mathrm{hm}^{2}$ designed irrigation area, which belongs to large irrigation district of country.

At present, the irrigation engineering mainly include the following sections. Firstly, the main diversion canal, $28.9 \mathrm{~km}$ length, has the entire whole section lining seepage, slope, the design water diversion capacity reach to $60 \mathrm{~m}^{3} / \mathrm{s}$. Maxin, Chaohe, Jianghe and Guotu, four main branch canal reach a length of $147 \mathrm{~km}, 89$ lateral canals, reach a length of $396 \mathrm{~km}$. Secondly, there are Yellow River gate and intercept sand gate, the intercept sand gate located in $1.8 \mathrm{~km}$ before the Yellow River gate, also three controlling gates located in Gujia, Niuwang and Wuqi Management stations, as well as a hub named Jiangji At the end of the canal, and more than 463 buildings. Thirdly, the main drainage channels in the irrigation district, including Tuhaihe, Chaohe, Maxinhe, Qinkouhe river and other 38 drainage channels upper the branch. Fourthly, there are several water storage projects, including Dongjiao, Longqihu, Qintai, Maojiawa reservoirs and other more than 40 water storage pits, the total storage capacity reach to 130 million $\mathrm{m}^{3}$. 


\section{Analysis of the existing problems}

In recent years, the coming water from Yellow River Basin decreased year by year, it is becoming more and more difficulty to maintain the design water supply reliability in the irrigation district, the contradiction between supply and demand is prominent [3]. Irrigation water use efficiency is lower than 0.5 , and the contradiction between upstream and downstream, industry and agriculture, production and living water in the irrigation district are prominent. In addition, unreasonable water storage and water irrigation in the area, causing the rise of ground water level, soil secondary salinization caused by the problem is still serious, and unreasonable drainage way led to the water ecological environment further deterioration, intensifying the problems of irrigation water shortage [4].

Due to the excessive use of pesticide and fertilizers in irrigation agriculture, the residue with flow into rivers and lakes and formed the agricultural non-point source pollution [5]. At present, the return water of farmland irrigation lead to environmental pollution, the problem such as regional water environmental problems appear constantly. There are a lot of waste and sewage in the irrigation district discharged arbitrarily, at the same time, irrigation return water carrying large amount of nitrogen and phosphorus into surface and groundwater, causing the exceeding standard of nitrogen and phosphorus in surface water and groundwater generally. Agricultural non-point source pollution has become the main pollution sources of channels in irrigation district.

Excess exploitation of water in upstream leading to the downstream flow decreasing, and the Yellow River slows down, so the river channel of the hydrological environment under the natural conditions are destroyed, common damage situation including zero flow of lower reachs of the river, sediment deposition, narrow flow section and so on, which will seriously affected the downstream and the surrounding ecological environment of agricultural production. In addition, in order to reduce leakage and loss in the process of water, it is commonly to lay the engineering such as concrete and masonry on main channel, however, the ecological functions of ditches are weakened, the soil and biological separated from drainage, river canal lost self-purification ability, which lead to the deterioration of ecological environment directly [6].

Due to the influence of traditional planned economy system, it is difficult to establish the mechanism of water price adjustment based on market supply and demand and cost changes, thus lead to the serious deviate from the cost of water price and water supply. At the same time, water rate collection and water metering is not standard, it is failed to play the function of water rate economic leverage. Since 1982, Handun irrigation district has been carrying out paid for the water supply, water measurement method for the irrigation district management unit to the county, the water price according to the charge to the county, due to water consumption under the lateral canal can not measurement, the county water fee payable by mu evenly spread to the villagers, then the financial departments collected by degrees and assigned to the irrigation district. However, the lower water price and non-standard water management lead to the lack of enough money to projects supporting the construction and maintenance by the water administrative department directly.

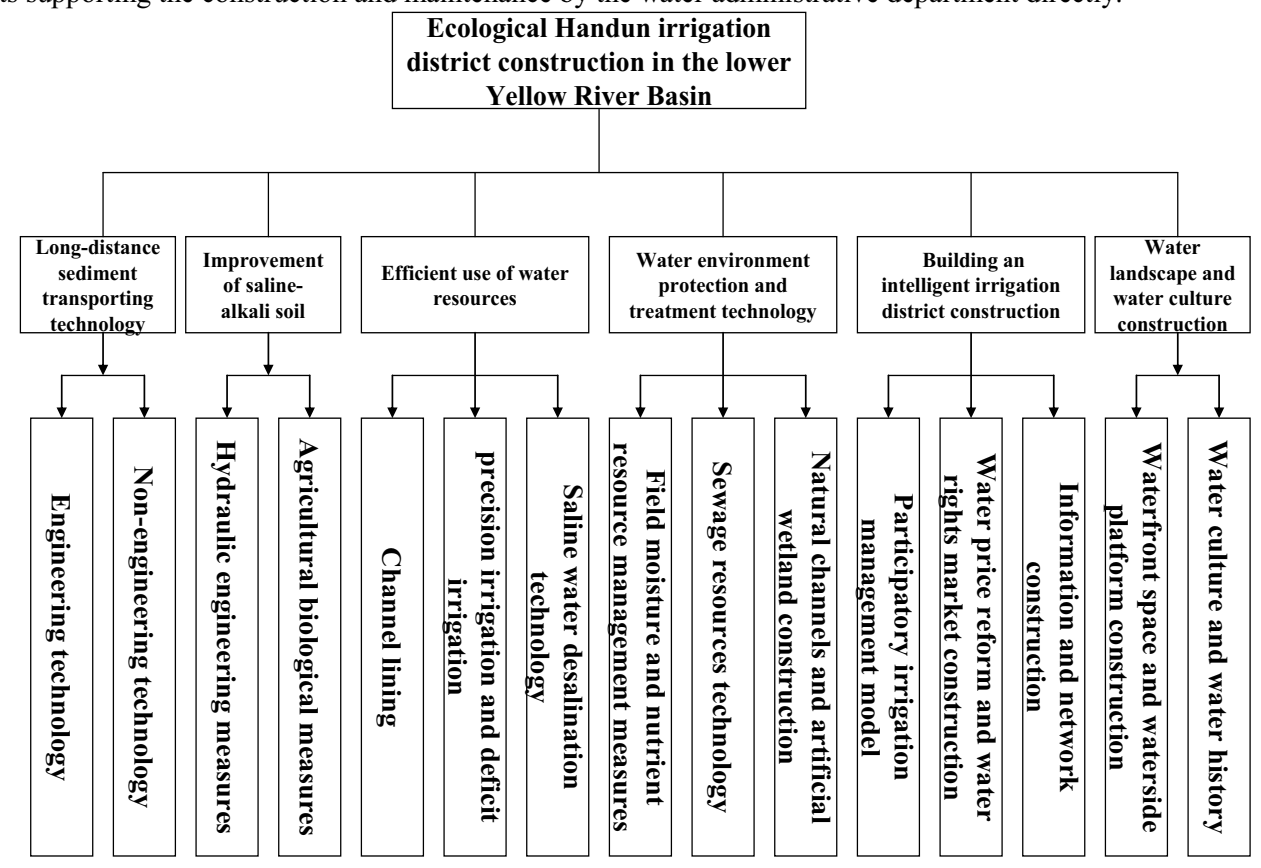

Fig. 1. Technical system framework of ecological Handun irrigation district construction

\section{Results}


As is shown in the figure 1, Firstly, long-distance sediment transporting technology in the lower Yellow River Basin irrigation district should be accepted. Sediment deposition is one of the major problems in the lower Yellow River Basin irrigation district, how to improve the ability of channel sediment is the key technology of distributing and deploying sediment over a long distance, including the block sand sluice engineering in Handun canal head, cross section shape optimization, channel lining engineering technology such as longitudinal slope and roughness set, as well as water diversion of joint scheduling of water and sediment discharge conditions, non-engineering technology such as water-saving and sediment reduction.

Secondly, it is important to improve comprehensive management of saline-alkali soil in the Yellow River irrigation district. It is suggested that in order to build an improved and optimized integrated technical system of salinization soil resources in the Yellow River irrigation district, we should accord to the principles of adaptation to local conditions and comprehensive prevention, as well as water conservancy engineering measures combine with agricultural biological engineering measures. Two measureas are applied, including hydraulic engineering measures, such as perfecting the irrigation and drainage facilities, controlling salt migration, Subsurface pipe draining off water and salt, decreasing groundwater level, flatting framland, building platform field, also agricultural biological measures, such as water-saving agriculture, increasing organic fertilizer, salt tolerance plant and breeding salt-tolerant varieties, and so on.

Thirdly, Several methods are proposed to improve the utilization efficiency of water resources in the Yellow River irrigation district. Researching new materials, new technology, new standards of channel lining, integrating application of precision irrigation control technology and new theory of the deficit irrigation, building efficient water-saving regulation technology and promotion mode, developing saline water desalination technology in shallow groundwater buried area, proposing multi-water resources joint configuration theory and regulation decision-making method, which embody sustainable utilization of water resources, social and economic development and ecological environment friendly[7].

Fourthly, Water environment protection and comprehensive treatment technology need to be adopted in the Yellow River irrigation district. First of all, field moisture and nutrient resource management measures such as factors influencing the pollutant migration should be analyzed, agricultural non-point source pollution control of the sewage sludge management technology system are established. Then, it is necessary to explore sewage resources technology and method, which is suitable for small enterprises, village life, small-scale livestock and poultry farms. Finally, it would like to study on non-point source pollutants from farmland to nearby water ditch wetlands intercept and removal mechanism in the process of migration, and establish channels of natural and artificial wetland construction technical programme, it is "reducing the pollution - source controlling - intercepting - conducting - repairing", thus water environment of irrigation district are improved.

The fifth, it would like to building an intelligent Yellow River irrigation district. it is necessary to Explore irrigation water management mode accord with the practice of irrigation district, dynamic, scientific and reasonable, proposing the participatory irrigation management model of "administrative organization - water users association - farmers", improving water price forming mechanism, establishing agricultural water subsidies and reward system, building the water rights market, promoting efficient use of water resources. It is important to etablish irrigation system of water monitoring and dispatching system, also irrigation district environment monitoring system and information network should be created, as well as the ecological irrigation system for information management and other advanced technology need to be researched.

In the end, it need to accelerate the Water landscape and water culture construction of Yellow River irrigation district. First of all, according to the goal of integrated multiple functions in irrigation district, it is necessary to research four waterfront sapce modes including main town canal, river, lake, wetland and four kind of ecological waterscape types including paddle type, enjoy water type, cognitive and recreation and so on. Then, full investigation and digging of water conservancy and water culture, religious belief, classic water conservancy scientific literature and poetry, stone inscription, historical records and legend, idiom, proverb, construction and other water culture resources, exploring the irrigation area water culture building framework, principle and its reasonable form.

\section{Discussion}

It is necessary to adopt the concrete measures of ecological irrigation district construction. The first is engineering measures, including main canal lining, check gate and intake sluice maintenance of main canal, building new management and canal bank road, upgrading substation and power distribution unit. In order to control main canal seepage, on the basis of the vegetative retaining wall brick with concrete to protect inner slope angle, at the same time, increasing water line and pure soil protective layer. The second is management measures, in order to enhance irrigation district management level, the main measures are rely to advanced technology. First of all, we need to establish a set of computer automatic monitoring system, the system include measuring water system and water control system, at the same time, it is necessary to equip monitoring machine to implement the collaborative scheduling in the irrigation district management office, multiple management not only can greatly save manpower, but also can improve efficiency and comprehensive benefits in terms of supply and demand of water. The third is ecological measures, it mainly include establishing three-dimensional botanical retaining body and wetland ecological area. Cultivating plant near the surface and planting grass in the water, aquatic plants can stop the sediment brought up by wind and hydraulic for a long time, then send accumulating sediment back in the water, which can provide nutrients required for aquatic plants and improve the water self-purification ability, also adjust the structure of the ecosystem circulation. Through planting aquatic plants such as algae, duckweed to establish 
wetland ecosystem, not only can improve the nitrogen and phosphorus pollutants absorption ability, but also can beautify the landscape of irrigation district [8].

\section{Conclusions}

Compared with the traditional irrigation, ecological irrigation district has the more complex and more comprehensive function, it should implement efficient utilization of soil and water resources, pay more attention to the water ecological environment protection and biodiversity maintenance, rational allocation of resources, maintaining the sustainable development of the irrigation district. In this paper, Handun Irrigation District in the lower Yellow River Basin, as the research object, Through analyzing the present operation situation and the existing problems, the technical system of ecological irrigation district in the lower Yellow River Basin are constructed, after that a series of the feasibility measures are proposed, including engineering measures, management measures and ecological measures, which has an important reference value for ecological irrigation district construction in the lower Yellow River Basin.

\section{Acknowledgements}

This work was financially supported by Shandong Natural Science Foundation(NO. ZR2014EEQ020) and Shandong Water Conservancy Science and Technology Practice Project(NO. SDSLKY201502).

\section{References}

1. P. L. Yang, Y. K. Li, X. H. Zeng, J. H. Yang, Q. Guo, S. M. Ren and Y. P. Su: China Water Resources. Vol. (14)(2009), p. 32-35

2. B. J. Gu, C. Wang and P. F. Wang: China Rural Water And Hydropower. Vol. (12) (2005), p.7-9

3. J. M. Goncalves, L. S. Pereira, S. X. Fang and B. Dong: Agricultural Water Management. Vol. 94(1-3)(2007), p. 93-108

4. Z. Z. Feng, X. K. Wang and Z. W. Feng: Agricultural Water Management. Vol. 71(2)(2005), p. 131-143

5. J. C. Valenzuela: Agricultural Water Management. Vol. 96(2)(2009), p. 188-194

6. B. J. Gu: China Rural Water and Hydropower. Vol. (10)(2006), p. 4-6

7. D. Xu and S. H. Gong: Journal of Hydraulic Engineering. Vol. 38(7)(2007), p. 806-811

8. B. J. Gu, C. Wang and P. F. Wang: Journal of Hydraulic Engineering. Vol. 37(2)( 2006), p. 178-183 